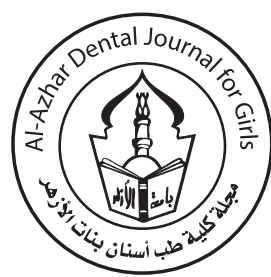

\title{
Evaluation of Shear Bond Strength of Self-Adhering Flowable Composite to Mineral Trioxide Aggregate and Biodentine
}

\author{
Asmaa O. Abdel-Rhman ${ }^{1}$, Mohsen N. El-Din ${ }^{2}$, Mahmoud H. Mohamed ${ }^{3}$
}

Codex : 21/1904

azhardentj@azhar.edu.eg

http://adjg.journals.ekb.eg

DOI: $10.21608 /$ adjg.2019.5919.1033

\begin{abstract}
Purpose: This study aimed to evaluate shear bond strength of mineral trioxide aggregate and biodentine to self-adhering flowable composite. Materials and Methods: eighty Double Split Teflon mold has been prepared with a central hole measuring $(3 \mathrm{~mm}$ in diameter and $2 \mathrm{~mm}$ in height) for the mold used for tested materials and ( $2 \mathrm{~mm}$ in diameter and in height) for the other mold used for restorative material. The molds were filled with MTA and Biodentine. The mixing material MTA and biodentine applied to its mold $(n=40)$ and allocated into 2 groups. The specimens will store for 72 hours at $37^{\circ} \mathrm{C}$ and $100 \%$ humidity. After 72 hours, self-adhering flowable composite was applied over MTA and Biodentine with a height and diameter each of $2 \mathrm{~mm}$. The samples were stored in Incubator for 24 hours at $37^{\circ} \mathrm{C}$ to enhance setting and then removed from the mold. SBS was measured in a universal testing machine with a load cell of $5 \mathrm{kN}$ and a crosshead speed of $0.5 \mathrm{~mm} / \mathrm{min}$. Data were analyzed using Graph Pad Instat. A value of $\mathrm{P} \leq 0.05$ was thought statistically significant. After homogeneity of variance and normal distribution of errors had been confirmed, student t-test was done for compared pairs. Chi square test was performed for failure mode analysis. Results: self-adhering flowable composite-Biodentine groups showed non significantly higherSBSvaluesthan the group made of self-adhering flowable composite-MTA(P>.05). Conclusion Biodentine exhibited higher SBS than MTA; therefore, they could be preferred under flowable composites.
\end{abstract}

\section{INTRODUCTION}

Restoration and preservation of dental health through proper restorative treatment modalities is the main objective of restorative dentistry

to protect the pulp and its function. This target is fullfilled by vital pulp
Self-Adhering Flowable

Composite, Biodentine,

Mineral Trioxide Aggregate.

- Paper extracted from Master thesis entitled Evaluation of Shear Bond Strength of Self-adhering Flowable Composite to Mineral Trioxide Aggregate and Biodentine.

1. Dentist at Ministry of Health.

2. Professor of Endodontics, Dental Medicine Faculty for Girls, Al-Azhar University.

3. Professor of Endodontic, Dental Medicine Faculty for Boys, Assiut branch, Al-Azhar University 
therapy in opened apex teeth to permit apexogenesis and normal development of the root and by pulp capping in mature teeth to avoid root canal therapy and the subsequent extensive restorations ${ }^{(1)}$.

Through apexogenesis and apexification steps and repairing of root perforations, a suitable material is put close to the connective tissues because it will make barrier against bacterial microleakage and repair tooth structure. Materials biocompatibility used in such situation is a most significant demand. So chosen material must supply a good seal against bacteria and fluids, induce bone deposition, liberate calcium hydroxide, liberate calcium hydroxide, set in a wet environment, have antibacterial property, be unchanged by blood contamination and have logical hardness and compressive strength ${ }^{(2)}$.

A choice material for retrograde filling, pulp capping, perforation repair, pulpotomy and as barrier apically for endodontic root canal with open apices in immature teeth which has been submitted is Mineral Trioxide Aggregate ${ }^{(1)}$.

In dentistry in 1993, Mineral trioxide aggregate (MTA), which first utilized, was composed of combination of tricalcium silicate, tetracalcium aluminoferrite, tricalcium aluminate, dicalcium silicate and bismuth oxide.

MTA has many advantages such as biocompatibility, setting in the existence of blood, capability of setting in a wet environment, safely when put adjacent to periodontal tissues and pulp, bacterial leakage prevention, low solubility, calcium hydroxide liberation and aids cementum re-growth by preparing environment for that, so it has attracted great attention. Long setting times and difficult handling are the main disadvantages of MTA ${ }^{(3)}$.

Lately, to avoid disadvantages of MTA, new calcium silicate-based materials have been advanced. Biodentine is one of new calcium silicate-based materials which composed of tricalcium silicate, zirconium oxide and calcium carbonate. Liquid contains a water-reducing agent and calcium chloride ${ }^{(4)}$.
High viscosity, ease of handling, better physical properties, besides having raw material with a known degree of purity and shorter setting time (12 minutes) are the main advantages of Biodentine above MTA. Biodentine has color stability, not genotoxic, low cytotoxicity, maintaining gingival fibroblast viability and when exposed to tissue fluids it induces the hydroxyapatite deposition on its surface. Also Biodentine induced the tertiary dentin formation and in the little invitro studies, Biodentine had compatibility to dental pulp cells. It also causes mineralization foci formation and differentiation of the pulp cells that cultured into odontoblast-like cells, likeness to MTA and calcium hydroxide ${ }^{(5)}$.

Newly, self-adhering flowable composites which merge an all-in-one a flowable composite and bonding system have been advanced. By this system, the demand for an additional adhesive application was removed. Some advantages of self-adhering flowable composite is minimizing handling errors, saving treatment chair time and heling in treatment of uncooperative patient because of bonding agent was Incorporated into a flowable composite. Selfadhering flowable composite is specific for class $\mathrm{V}$ cavities, noncarious lesions cervically, small class I cavities and in class I and II restorations as lining due to it is restorative material with an adhesive-free ${ }^{(6)}$.

It is imortant that the success of restorations and the goodness of the filling are been related to the bond strength of restorative material to pulp capping materials ${ }^{(7)}$. Furthermore, bonding between composite resins and pulp capping biomaterials which have proper bonding creates the adhesive joint, that has ability for spreading stress over the complete area of the bond evenly ${ }^{(8)}$.

\section{MATERIALS AND METHODS}

Mineral trioxide aggregate (Dentsply, Tulsa, Johnson City, USA), Biodentine (Septodont; Saint Maur des Fosses, France), Self-adherive flowable composites (Vertise Flow, Kerr, Orange, CA, Italy), were used in this study. 


\section{Sample preparation:}

Eighty Double Split Teflon mold was prepared with hole in the center about (2 Millimeters in height and 3 Millimeters in diameter) for the mold A used for tested materials and (2 Millimeters in height and diameter) for mold B used for restorative material. The materials investigated are a ProRoot MTA and Biodentine. For preparation, ProRoot MTA, $1.00 \mathrm{~g}$ of ProRoot MTA powder was mixed $0.33 \mathrm{~g}$ of water which distilled. For Biodentine preparation, the powder and 5 drops of the liquid provided was mixed inside the plastic capsule brought by the manufacturer and then mechanical mixing for 30 seconds using the amalgamator on $4500 \mathrm{rpm}$.

Material that mixed was applied to its mold and then a wet cotton pellet was covered it. The samples were kept at $37^{\circ} \mathrm{C}$ and incubator for 72 hours. For creating a standard layer of specimens, 400-grit paper was used to polish all prepared surfaces for 60 seconds. After 72 hours, Vertise Flow was applied over MTA and Biodentine with $2 \mathrm{~mm}$ of height and diameter by a plastic cylinder. The surface area was placed over the previously prepared surfaces. In the rings, Vertise Flow was placed inside it and cured with a light emitting diode from the side of the cylinder, according to the recommendations of manufacturer.The specimens were kept in Incubator at $37^{\circ} \mathrm{C}$ to enhance setting for 24 hours and then removed from the mold.

\section{Sample grouping:}

The samples were allocated into 2 groups, Group I: MTA $(n=40)$, Group II: Biodentine $(n=40)$.

\section{Measurement of Shear bond strength:}

To evaluate the bond strength, shear test of a circular interface was prepared. All models were individually and horizontally connected to testing machine by a computer controlled materials with a load cell of $5 \mathrm{kN}$ and data were been printed using software of computer. Samples were bound to test- ing machine by the lower fixed compartment with tightening screws. Test of Shearing was done by load compressive mode used at BD-Resin interface and MTA-Resin interface using chisel shaped metallic rod with a mono-bevelled connected to testing machine at the upper movable compartment which travelling at cross-head speed of $0.5 \mathrm{~mm} / \mathrm{min}$. The load needed to debonding was noted in Newton.

\section{Failure modes evaluation:}

Stereomicroscope was used for evaluating failure modes at 40magnification. Classification of Failure modes were into three types: adhesive mode: $100 \%$ adhesive failure among a self adhesive flowable composite and tested material, cohesive mode: $100 \%$ cohesive failure inside a self adhesive flowable composite or tested material, and mix mode: mixed failure collected adhesive and cohesive failure of tested materials or a self adhesive flowable composite.

\section{STATISTICAL ANALYSIS}

The results were analyzed using Graph Pad Instat (Graph Pad, Inc.) software for windows. A value of $\mathrm{P} \leq 0.05$ was thought statistically significant. Continuous variables were been expressed as the mean values and standard deviation. After homogeneity of variance and normal distribution of errors had been confirmed, student t-test was done for compared pairs. Chi square test was been done for failure mode analysis. Sample size $(\mathrm{n}=20)$ was large enough to detect large effect sizes for main effects and pairwise comparisons, with the satisfactory level of power set at $80 \%$ and a $95 \%$ confidence level.

\section{RESULTS}

\section{Shear bond strength}

In descriptive statistics, mean values and standard deviations (SD) for shear bond strength have been shown and measured with mega Pascal (MPa) recorded for both groups are summarized in table (1). 
Table (1): Descriptive statistics of shear bond strength (Mean values and SD) for both groups

\begin{tabular}{|c|c|c|c|c|c|c|}
\hline \multicolumn{2}{|c|}{ Variable } & Mean \pm SD & \multirow{2}{*}{ SEM } & \multirow{2}{*}{ Median } & \multicolumn{2}{c|}{ Range } \\
\cline { 5 - 7 } & & & & & \\
\hline \multirow{2}{*}{ Material group } & Biodentine & $6.006 \pm 1.12$ & 0.55 & 6.163473 & 3.832869 & 8.110861 \\
\cline { 2 - 7 } & MTA & $5.364 \pm 1.38$ & 0.67 & 4.941208 & 3.532623 & 7.851022 \\
\hline
\end{tabular}

It was found that the shear bond strength mean values and SD recorded for Biodentine group were $(6.006 \pm 1.12 \mathrm{MPa})$ with minimum value $(3.832869$ $\mathrm{MPa})$ and maximum value $(8.110861 \mathrm{MPa})$. Meanwhile the shear bond strength mean values and SD recorded for MTA group were (5.364 \pm 1.38 $\mathrm{MPa})$ with minimum value(3.532623 $\mathrm{MPa})$ and maximum value (7.851022 $\mathrm{MPa})$.

It was resulted that group of Biodentine recorded non-significant statistically higher mean value $(6.006 \pm 1.12 \mathrm{MPa})$ than MTA group mean value $(5.364 \pm 1.38 \mathrm{MPa})$ as indicated by unpaired t-test $(\mathrm{p}=0.4724>0.05)$.Table (2).
Failure modes analysis

In Biodentine group the observed modes of failure were predominantly mixed mode $(71.42857 \%)$ with little cohesive and adhesive modes (14.28571\%) for both.

In MTA group the majority of failure modes observed were mixed mode $(85.71429 \%)$ while minority of failure modes observed were adhesive modes $(14.28571 \%)$ with no record for cohesive failure $(0 \%)$

Chi square test showed significant difference in failure mode distribution between both group $(\mathrm{p}=0.0004<0.5)$.Table $(3)$.

Table (2): Comparison of shear bond strength (Mean $\pm S D)$ between both groups

\begin{tabular}{|c|c|c|c|c|c|c|}
\hline \multicolumn{2}{|c|}{ Variable } & \multirow{2}{*}{ Mean \pm SD } & \multicolumn{2}{c|}{ 95\% CI } & \multicolumn{2}{c|}{ Statistics } \\
\cline { 4 - 7 } & & Low & High & t-value & P value \\
\hline \multirow{2}{*}{ Material group } & Biodentine & $6.006 \pm 1.12$ & 4.667 & 7.34 & \multirow{2}{*}{0.74} & $0.4724 \mathrm{~ns}$ \\
\cline { 2 - 5 } & MTA & $5.364 \pm 1.38$ & 3.772 & 7.007 & & \\
\hline
\end{tabular}

*; significant $(p<0.05)$

ns; non-significant $(p>0.05)$

Table (3): Comparison of frequent distribution of failure modes analysis (\%) between both groups

\begin{tabular}{|c|c|c|c|c|c|c|}
\hline \multirow{2}{*}{} & \multicolumn{3}{c|}{ Failure mode } & \multicolumn{2}{c|}{ Chi square test } \\
\cline { 3 - 7 } & Cohesive & Adhesive & Mixed & Chi value & P value \\
\hline \multirow{2}{*}{$\begin{array}{c}\text { Material } \\
\text { group }\end{array}$} & Biodentine & 14.28571 & 14.28571 & 71.42857 & \multirow{2}{*}{15.5} & $0.0004 *$ \\
\cline { 2 - 7 } & MTA & 0 & 14.28571 & 85.71429 & \\
\hline
\end{tabular}




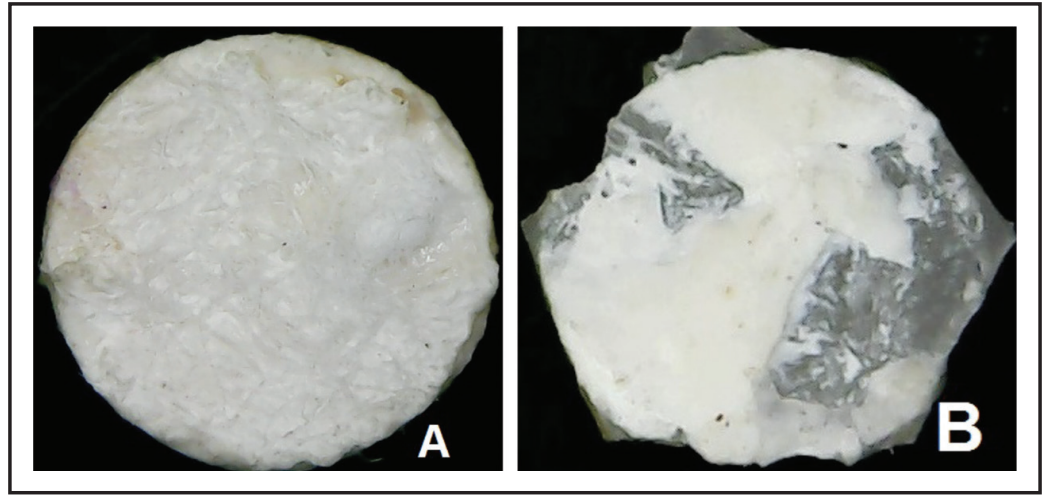

Figure (1): Photograph showing imaging of Steriomicroscopic of the failure modes. (A) Adhesive failure in Biodentine. (B) Mix failure in Biodentine.

\section{DISCUSSION}

The success of MTA and Biodentine is superior in the varied endodontic applications. However, because of their high physical properties and excellent biocompatibility, elevated clinical success has been showed. For this cause, big importance for bond strength of calcium silicate cements to restorative materials in clinical success. High SBS values demonstrae high bonding of the restorative material to cement, which produces less microleakage ${ }^{(9)}$.

Along the years, in varied clinical applications in public dentistry as direct and indirect pulp capping, pulpotomy methods, repair of furcation, internal resorption of root and traumatic restorative treatment, MTA has been used in all this application. Biodentine is recent material have been advanced. Biodentine and MTA have the same composition chemically. Biodentine can be applied in any cases in that MTA is utilized. In addition to this material has many advantages such as bioactivity, remineralization properties and biocompatibility, the bond strength of those materials to restorative material is significant ${ }^{(3)}$.

The most common procedure for achieving of high the adhesive properties of restorative materials is estimation of the bond strength. There are different test methods utilized in the literature for bond strength. One of the most methods repeatedly used in the literature is the shear bond strength. The SBS test is usually preferred since the test method and the test samples are simpler to prepare with minimal equipment. However, there are disadvantages like non-uniform stress distributions in the bond region ${ }^{(9)}$. In our study, the SBS test, one of the repeatedly used methods in the literature, was used to estimate the bond strength between Biodentine to composite and MTA to composite.

The adhesive joint which has ability for spreading stress over the complete bond region evenly, creates proper bonding between composite resins and pulp capping biomaterials. The influence of different techniques of restoration on the bond strength of MTA was been demonstrated in numerous studies. However, the bond strength between composites and Biodentine were been published in little reports with experimental data ${ }^{(10)}$.

MTA specimens and Biodentine specimens were been kept at incubator for 72 hours for completing setting of the materials, in the present study. Due to low initial compressive strength of MTA, etchand-rinse adhesive application of over MTA be delayed for 96-h and application of low condensation forces for coronal restoration above MTA according to studies of investigators ${ }^{(11)}$. Compression forces and surface pretreatment before bonding were not needed for application of the new FC (VF) due to it has both an adhesive and a composite. 
Some authors recommended that capable of desirable sealing of MTA has been reached after 72 hours at least. Also it demonstrated that Biodentine takes 12 minutes for the initial setting reaction after the powder and the liquid were mixed. However, Biodentine was reached complete maturation after 2 weeks ${ }^{(9)}$. In other study, the shear bond strength of composite to Biodentine was evaluated afterward 2 time periods (ie, 12 minutes and 24 hours) and SBS value was been increased after the 24-hour period ${ }^{(12)}$.

In the present study, 400-grit paper was been used for polishing the MTA surfaces for $60 \mathrm{sec}$ onds to create a standard layer of the specimens. However, in previous researches, increasing bond strength was related to surfaces of MTA were not rinsed or polished so rough surfaces was produced. Differences in the method used studies may possibly lead to the various results obtained from varied studies. Some authors estimated the SBS of compomer and composite utilizing various adhesives to MTA and found that an SBS value of 1-step self-etch adhesive was $10 \mathrm{MPa}{ }^{(7)}$. Some studies used different adhesive systems to compare the SBS of MTA to composites and exists that SBS value of 1-step selfetch adhesive was $5 \mathrm{MPa}{ }^{(13)}$. Another author used 1-step self-etch adhesive and reported that a value of SBS for a composite to MTA and found an SBS value was $13 \mathrm{MPa}{ }^{(14)}$.

Shear Bond Strength value of Biodentine to Vertise Flow was $6 \mathrm{MPa}$ in my current study, which is lower greatly than previous studies the value. The SBS between Biodentine and different adhesive systems was described in previous study that showed a value of SBS for these materials changed from 15 to $19 \mathrm{MPa}^{(12)}$. In this study, Shear Bond Strength value of MTA to Vertise Flow was 5.3MPa. In previous studies reported that Adper Single Bond demonstrated a value of SBS was $2.76 \mathrm{MPa}$ in case MTA surface was not etched ${ }^{(8)}$.

In the present study, Vertise Flow depends on adhesive monomer glycerol phosphate dimethacrylate in bonding mechanism. The adhesive monomer glycerol phosphate dimethacrylate mainly connects ions of calcium.The phosphate group is responsible for acid etching. The dimethacrylate plays role in supplying mechanical strength of the adhesive material where cross-linking reactions contains the dimethacrylate functional groups with other methacrylate monomers. Dental substrate can be predictably to interact with Vertise Flow like mild self-etch adhesives. Modification on enamel surface might be increased capacity of the bonding of Vertise Flow according to the manufacturers while methodes of improving the bond strength of Vertise Flow to pulp capping materials did not found. SO Thus, any surface treatment did not put on MTA and Biodentine $^{(15)}$.

In previous study showed the Shear Bond Strength between composites and MTA can be elevated with etch and rinse adhesives ${ }^{(3)}$. However, some studiesfound that SBS to MTA was higher with 1-step self-etch adhesives than etch-and-rinse adhesives and 2-step self-etch adhesives ${ }^{(16)}$. Some authors reported that SBS to Biodentine with 2 step self etch adhesives are higher than etch and rinse adhesives and 1 step self etch adhesives and ${ }^{(12)}$.

In previous studies, cohesive failure was resulted in approximately half of the specimens and adhesive failure was resulted in the residual half of the specimens in MTA and Biodentine. However, specimens of MTA exhibited the majority of failure modes were mixed mode while minority of failure modes were adhesive modes with no record for cohesive failure adhesive failure, and specimens of Biodentine exhibited predominantly mixed failure with little cohesive and adhesive mode in my present study. The accurate interfacial bond strength of the adhesive resin to the pulp capping material does not necessarily be inverted by this finding. Consequently, if cohesive failure would not occur in this study, calcium silicate based materials used may exhibit higher SBS to Vertise Flow. The bond will be acceptable if failure occurs inside each material instead of in the bonded interface (cohesive instead of adhesive) that it is demonstrated in a previous study. 
SBS values of Biodentine to the composites showed higher than SBS values of MTA to the composites. Therefore, the hypothesis was accepted. Changes were not statistically significant between two grous. As obvious, general opinion of authors on the suitable resin materials for MTA and Biodentine have not reached where in many studies, very different results have been demonstrated. Thus, we will be needed for further studies.

\section{CONCLUSION}

The following could be concluded within the limitations of this study:

1- Self-adhering flowable composite has shown superior shear bond strength to Biodentine than MTA.

2- The mode of failure was mixed mode within Biodentine and MTA.

\section{REFERENCES}

1. Oskoee SS, Bahari M, Kimyai S, Motahhari P, Eghbal MJ, and Asgary S. "Shear Bond Strength of Calcium Enriched Mixture Cement and Mineral Trioxide Aggregate to Composite Resin with Two Different Adhesive Systems." J Dent 2014; $11:$ 665-71.

2. Kayahan MB, Nekoofar MH, Kazandag̀ M, Canpolat C, Malkondu O, Kaptan F, and Dummer PMH. "Effect of Acid-Etching Procedure on Selected Physical Properties of Mineral Trioxide Aggregate." Int Endod J 2009; 42 : 1004-14.

3. Altunsoy M, Tanriver M, Ok E, and Kucukyilmaz E. "Shear Bond Strength of a Self-Adhering Flowable Composite and a Flowable Base Composite to Mineral Trioxide Aggregate, Calcium-Enriched Mixture Cement, and Biodentine." J Enodd 2015; 41 : 1691-95.

4. Ajas, A, Babu A, Varughese JM, Amal S, and Thaha KA. "Biodentine - An Alternative to MTA?" Arch Dent Med Res 2016; 2 : 26-33.

5. Sayed MM, Khattab NMA and Ahmed WH "Histopathological and Histochemical Evaluation of
Pulpal Response to Biodentine Compared to Portland Cement in Pulpotomized Dogs' Teeth" 2018; 3: 261-72.

6. Goracci C, Margvelashvili M, Giovannetti A, Vichi A, and Ferrari M. "Shear Bond Strength of Orthodontic Brackets Bonded with a New Self-Adhering Flowable Resin Composite." Clin Oral Investig 2013; 17 :609-17.

7. Tunç ES, Bayrak S, and Eğilmez T. "The Evaluation of Bond Strength of a Composite and a Compomer to White Mineral Trioxide Aggregate with Two Different Bonding Systems." J Endod 2008; 34 : 603-5.

8. Oskoee SS, Kimyai S, Bahari M, et al. "Comparison of Shear Bond Strength of Calcium-Enriched Mixture Cement and Mineral Trioxide Aggregate to Composite Resin.” J Contemp Dent Prac 2011; 12 : 457-62.

9. BULDUR B, ÖZNURHAN F, KAYABAŞI M, and ŞAHIN F. "Shear Bond Strength of Two Calcium SilicateBased Cements To Compomer." Cumhuriyet Dent J 2018; 21:18-23.

10. Jaberi-Ansari Z, Mahdilou M, Ahmadyar M, and Asgary S. "Bond Strength of Composite Resin to Pulp Capping Biomaterials after Application of Three Different Bonding Systems." J Dent Res, Dent Clin, Dent Prospect 2013; 7:152-56.

11. Hashem AAR and Amin SAW. "The Effect of Acidity on Dislodgment Resistance of Mineral Trioxide Aggregate and Bioaggregate in Furcation Perforations: An in Vitro Comparative Study.” J Endod 2012; 38:245-49.

12. Odabaş ME, Bani M, and Tirali RE. "Shear Bond Strengths of Different Adhesive Systems to Biodentine." Scien World J 2013.

13. Bayrak S, TUNÇ ES, Saroglu I, and Egilmez T. "Shear Bond Strengths of Different Adhesive Systems to White Mineral Trioxide Aggregate." Dent Mat J 2009; 28:62-67.

14. Atabek D, Sillelioglu H, and Ölmez A. "Bond Strength of Adhesive Systems to Mineral Trioxide Aggregate with Different Time Intervals.” J Endod 2012; 38:1288-92.

15. Poss SD. "Utilization of a New Self-Adhering Flowable Composite Resin.” Dent Today 2010; 29:104.

16. Neelakantan P, Grotra D, Subbarao CV, and Garcia-Godoy F. "The Shear Bond Strength of Resin-Based Composite to White Mineral Trioxide Aggregate." J Am Dent Assoc 2012; 143:e40-45. 